\title{
Biomarkers to identify sputum eosinophilia in different adult asthma phenotypes
}

\author{
Guus A. Westerhof ${ }^{1}$, Daniël A. Korevaar², Marijke Amelink', Selma B. de Nijs', \\ Jantina C. de Groot ${ }^{3}$, Junfeng Wang ${ }^{2}$, Els J. Weersink ${ }^{1}$, Anneke ten Brinke ${ }^{3}$, \\ Patrick M. Bossuyt ${ }^{2}$ and Elisabeth H. Bel ${ }^{1}$
}

\begin{abstract}
Affiliations: ${ }^{1}$ Department of Respiratory Medicine, Academic Medical Centre, Amsterdam, the Netherlands. ${ }^{2}$ Department of Clinical Epidemiology, Biostatistics and Bioinformatics, Academic Medical Centre, Amsterdam, the Netherlands. ${ }^{3}$ Department of Respiratory Medicine, Medical Centre Leeuwarden, Leeuwarden, the Netherlands.
\end{abstract}

Correspondence: G.A. Westerhof, Department of Respiratory Medicine, Room F5-260, Academic Medical Centre, University of Amsterdam, PO Box 22700, 1100 DE Amsterdam, The Netherlands.

E-mail: g.a.westerhofdamc.nl

ABSTRACT Several biomarkers have been used to assess sputum eosinophilia in asthma. It has been suggested that the diagnostic accuracy of these biomarkers might differ between asthma phenotypes. We investigated the accuracy of biomarkers in detecting sputum eosinophilia $(\geqslant 3 \%)$ in different adult asthma phenotypes.

Levels of eosinophils in blood and sputum, exhaled nitric oxide fraction (FeNO) and total immunoglobulin (Ig)E from 336 adult patients, enrolled in three prospective observational clinical trials and recruited at five pulmonology outpatient departments, were analysed. Areas under the receiver operating characteristics curves (AUC) for detecting sputum eosinophilia were calculated and compared between severe and mild, obese and nonobese, atopic and nonatopic and (ex-)smoking and never-smoking asthma patients.

Sputum eosinophilia was present in 116 patients (35\%). In the total group the AUC was 0.83 (95\% CI $0.78-0.87)$ for blood eosinophils, $0.82(0.77-0.87)$ for FeNO and $0.69(0.63-0.75)$ for total IgE. AUCs were similar for blood eosinophils and FeNO between different phenotypes. Total IgE was less accurate in detecting sputum eosinophilia in atopic and obese patients than in nonatopic and nonobese patients.

Blood eosinophils and FeNO had comparable diagnostic accuracy (superior to total IgE) in identifying sputum eosinophilia in adult asthma patients, irrespective of asthma phenotype such as severe, nonatopic, obese and smoking-related asthma.

@ERSpublications

FeNO and blood eosinophils can be used to detect sputum eosinophilia in adult asthma patients regardless of phenotype http://ow.ly/MnGqF

This article has supplementary material available from erj.ersjournals.com

Received: Jan 222015 | Accepted after revision: April 152015 | First published online: June 252015

Support statement: The sub-studies described in this manuscript were financially supported by an unrestricted grant from GlaxoSmithKline (SAS117256), a grant from Stichting Astma Bestrijding (Foundation for the Prevention of Asthma; 2012/010), a grant from the Lung Foundation Netherlands (3.2.08.027) and a grant from Stichting Longgeneeskunde Fryslân (Regional Foundation for Pulmonary Medicine). Funding information for this article has been deposited with FundRef.

Clinical trial: These studies are registered at www.trialregister.nl with identifier numbers NTR2217, NTR1846, NTR1838 and NTR 4589.

Conflict of interest: Disclosures can be found alongside the online version of this article at erj.ersjournals.com

Copyright OERS 2015 


\section{Introduction}

Eosinophilic airway inflammation is an important distinguishing characteristic of specific adult asthma phenotypes [1]. To assess this type of airway inflammation, sputum eosinophil counts are generally considered to be the gold standard [2]. Treatment guided by sputum eosinophils reduces the frequency of asthma exacerbations [3] and patients with sputum eosinophilia have a better response to inhaled corticosteroids with respect to reducing airway hyperresponsiveness, decreasing asthma symptoms and improving quality of life compared to those without $[4,5]$. Not surprisingly, the recent European Respiratory Society/American Thoracic Society guidelines on severe asthma recommend sputum eosinophils counts combined with clinical criteria to guide asthma therapy [6]. Unfortunately, sputum induction and differential sputum cell counts are only feasible in specialised clinics, are not always successful and do not give immediate results [7].

Several alternative methods of assessing airway eosinophilia have been proposed in the literature, including noninvasive biomarkers such as the exhaled nitric oxide fraction ( $F$ eNO) [8-10], peripheral blood eosinophil counts $[10,11]$ and total immunoglobulin $\mathrm{E}(\mathrm{Ig}) \mathrm{E}[10]$, with varying diagnostic accuracy. However, specific patient characteristics that distinguish between different adult asthma phenotypes such as asthma severity [12], obesity [13], atopy [14] and (ex-)smoking status [15] may influence both airway and systemic inflammation. Therefore, the accuracy of biomarkers to assess sputum eosinophilia may vary between these different asthma phenotypes.

The aim of the present study was to evaluate the diagnostic accuracy of FeNO, blood eosinophils and total IgE for detecting sputum eosinophilia, defined as $\geqslant 3 \%[16,17]$ in a large heterogeneous group of adult asthma patients, as well as in patients with different asthma phenotypes.

\section{Methods}

Patients

We collected data from 571 patients with adult-onset asthma (onset of asthma after the age of 18 years) who had been included in three separate observational clinical trials (Netherlands Trial Register numbers: NTR2217, NTR1846 and NTR1838) [18, 19] between 2009 and 2012. These prospective trials aimed at phenotyping patients with adult-onset asthma based on an extensive set of clinical, functional and inflammatory parameters. Patients aged $\geqslant 18$ years were eligible if they had a confirmed diagnosis of asthma based on international guidelines (history of variable respiratory symptoms and documented variable expiratory airflow limitation) [20]. Patients with other pulmonary diseases, unrelated major comorbidities, pregnancy or a smoking history of $>10$ pack-years combined with fixed airflow obstruction/reduced diffusion capacity were excluded. Detailed inclusion and exclusion criteria have been reported elsewhere $([18,19]$ and NTR2217). All eligible patients visiting the pulmonology outpatient department of four secondary and one tertiary referral clinic in the Netherlands were invited to participate. All three trials were reviewed and approved by medical ethical boards before their initiation. All patients gave informed consent. The present additional analysis was registered at the Netherlands Trial Register (NTR 4589).

\section{Assessment of specific phenotypic characteristics \\ Asthma severity}

Asthma severity was assessed according to the Innovative Medicines Initiative criteria [21], based on medication use and degree of asthma control. Severe asthma was defined by the use of $\geqslant 1000 \mu \mathrm{g} \cdot$ day $^{-1}$ fluticasone equivalent and/or daily oral corticosteroids plus a second controller, combined with an asthma control score $>1.5$ [22] on the JUNIPER et al. [23] asthma control questionnaire or at least two exacerbations in the past 12 months. Patients who did not fulfil these criteria were considered as having mild-to-moderate asthma.

Obesity

Obesity was defined as a body mass index $(\mathrm{BMI}) \geqslant 30 \mathrm{~kg} \cdot \mathrm{m}^{-2}$.

Atopy

Specific IgE to common aeroallergens was measured by immunoCAP; atopy was defined as specific $\operatorname{IgE}$ $>0.35 \mathrm{kU} \cdot \mathrm{L}^{-1}$ for at least one allergen.

\section{Smoking status}

Smoking status was recorded during history taking. (Ex-)smokers were either current or previous smokers. Nonsmokers were patients who had never smoked.

\section{Reference standard: sputum eosinophils}

Sputum induction was performed according to internationally accepted standards by trained lung function analysts [24]. All patients inhaled a nebulised saline solution for $5 \mathrm{~min}$; if possible this was repeated up to 
three times. Sputum processing was performed according to full sample method and differential cell counts were analysed on cytospin preparations. Results for different sputum cell types are presented as percentage of total nonsquamous cell count. Laboratory analyses were performed blinded to patient characteristics and index test results.

\section{Index tests: FeNO, blood eosinophils and total IgE}

FeNO (index test 1) was measured using a portable rapid-response chemoluminescent analyser (flow rate $50 \mathrm{~mL} \cdot \mathrm{s}^{-1}$; NIOX System, Aerocrine, Sweden). FeNO results are reported as parts per billion [25].

Venous blood was collected and differential white blood cells counts were performed. Absolute blood eosinophil numbers (index test 2) are reported as $10^{9}$ cells $\cdot \mathrm{L}^{-1}$. Total $\operatorname{IgE}$ (index test 3 ) was measured using immunoCAP tests and reported as $\mathrm{kU} \cdot \mathrm{L}^{-1}$. All measurements in blood samples were performed by the general laboratories of the participating hospitals, which were blinded to the outcome of other tests.

All data were collected in one or two visits $<2$ weeks apart.

\section{Statistical analysis}

Adequate sputum samples from 336 patients were available (online supplementary fig. E1: study flowchart) and these patients were included in the analyses of diagnostic accuracy. Baseline characteristics between patients with and without adequate sputum were compared. Patients with missing data on blood esoinophils, FeNO or total IgE were excluded for the analysis of that index test.

Receiver operating characteristic curve (ROC) analysis was used to evaluate the diagnostic accuracy of FeNO, blood eosinophils, total IgE and their combinations to identify sputum eosinophilia $\geqslant 3 \%$. This was done first in the complete group and thereafter in subgroups with specific phenotypic patient characteristics as described above. Analysis included the following: 1) area under the ROC curve (AUC) (95\% CI) for the different biomarkers (FeNO, blood eosinophils and total IgE); 2) sensitivity (95\% CI) and corresponding threshold of each biomarker at a specificity of $\geqslant 95 \%$; and 3) specificity (95\% CI) and corresponding threshold of each biomarker at a sensitivity of $\geqslant 95 \%$. McNemar's test was used to compare sensitivities and specificities between biomarkers. DeLong tests were used to compare AUCs between different asthma phenotypes and to evaluate whether combinations of any of the three biomarkers improved the diagnostic accuracy of each single biomarker.

We also developed a multivariate logistic regression model for the prediction of sputum eosinophilia $\geqslant 3 \%$ based on phenotypic features and the three markers. First, we evaluated whether patient characteristics (age, sex, BMI, asthma duration, race, smoking status, post-bronchodilator forced expiratory volume in $1 \mathrm{~s}$ (FEV1), post-bronchodilator FEV1/forced vital capacity (FVC) ratio, atopy status and medication use (high dose versus low dose)) were significantly associated with sputum eosinophilia in a univariate analysis $(p<0.20)$. With the significant characteristics we then built a multivariable logistic model. We then used a stepwise procedure to arrive at a parsimonious model by removing in each step the variable with the smallest Wald statistic, until further removal would lead to a significant loss in goodness-of-fit $(\mathrm{p}<0.05$; likelihood-ratio test). Then, the three markers were added to the resulting multivariable model, and the stepwise procedure was repeated.

Data were analysed using SPSS (version 22; IBM, Armonk, NY, USA) and R version 3.0 (R Foundation for Statistical Computing, Vienna, Austria).

\section{Results}

Table 1 shows the baseline characteristics of the 336 patients who were included in the analyses. Compared to these patients, the excluded patients $(n=235)$ were younger, more often female and had slightly lower blood eosinophils (online supplementary table E1). Sputum eosinophilia was present in 116 (35\%) patients. FeNO, blood eosinophils and total IgE were missing in ten, five and four of the included patients, respectively. Correlations of the three biomarkers with sputum eosinophils are shown in online supplementary figure E2.

\section{Diagnostic accuracy of biomarkers}

In the complete group as well as in the eight subgroups, FeNO and blood eosinophils had similar diagnostic accuracy, whereas the AUC for total IgE was significantly lower (tables 2 and 3). Combining FeNO and blood eosinophils significantly improved diagnostic accuracy compared to FeNO alone ( $\mathrm{p}=0.001)$ or blood eosinophils alone ( $\mathrm{p}=0.027$ ) (AUC $0.87,95 \%$ CI $0.83-0.91$; tables 2 and 3 , figs 1 and 2 ). Adding total IgE to the combination of FeNO and blood eosinophils did not significantly improve the AUC (0.87, $\mathrm{p}=0.732$ ). Total IgE performed significantly better in obese than in nonobese patients, and in nonatopic compared to atopic patients, respectively (table 3 and figure 2). 
TABLE 1 Baseline characteristics of patients who provided an adequate sputum sample

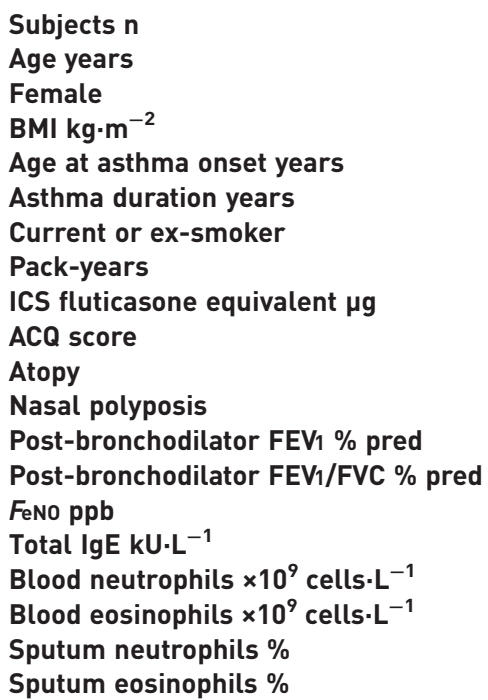


TABLE 2 Diagnostic accuracy of the biomarkers in the complete group

\begin{tabular}{|c|c|c|c|c|c|c|c|c|c|c|}
\hline Test & $\begin{array}{c}\text { AUC } \\
(95 \% \mathrm{CI})\end{array}$ & $\begin{array}{l}\text { Positivity } \\
\text { threshold }\end{array}$ & $\begin{array}{c}\text { Sensitivity } \\
(95 \% \mathrm{CI})\end{array}$ & $\begin{array}{c}\text { Specificity } \\
(95 \% \mathrm{CI})\end{array}$ & PPV $(95 \% \mathrm{CI})$ & NPV $(95 \%$ CI) & $\begin{array}{c}\text { True } \\
\text { positive }\end{array}$ & $\begin{array}{c}\text { False } \\
\text { positive }\end{array}$ & $\begin{array}{c}\text { False } \\
\text { negative }\end{array}$ & $\begin{array}{c}\text { True } \\
\text { negative }\end{array}$ \\
\hline \multirow[t]{2}{*}{ FenO } & $0.82(0.77-0.87)$ & $\geqslant 12.2 \mathrm{ppb}$ & $0.96(0.90-0.99)$ & $0.28(0.22-0.34)$ & $0.41(0.35-0.47)$ & $0.92(0.82-0.97)$ & 108 & 154 & 5 & 59 \\
\hline & & $\geqslant 64.5 \mathrm{ppb}$ & $0.39(0.30-0.49)$ & $0.95(0.92-0.98)$ & $0.81(0.68-0.90)$ & $0.75(0.69-0.80)$ & 44 & 10 & 69 & 203 \\
\hline \multirow[t]{2}{*}{ Blood eosinophils } & $0.83(0.78-0.87)$ & $\geqslant 0.09 \times 10^{9}$ cells $\cdot L^{-1}$ & $0.96(0.90-0.99)$ & $0.26(0.20-0.33)$ & $0.40(0.34-0.46)$ & $0.92(0.81-0.97)$ & 108 & 161 & 5 & 57 \\
\hline & & $\geqslant 0.41 \times 10^{9}$ cells $\cdot \mathrm{L}^{-1}$ & $0.36(0.27-0.46)$ & $0.95(0.91-0.97)$ & $0.79(0.65-0.88)$ & $0.74(0.69-0.79)$ & 41 & 11 & 72 & 207 \\
\hline \multirow[t]{2}{*}{ Total IgE } & $0.69(0.63-0.75)$ & $\geqslant 13.5 \mathrm{kU} \cdot \mathrm{L}^{-1}$ & $0.96(0.90-0.99)$ & $0.28(0.22-0.34)$ & $0.41(0.35-0.47)$ & $0.92(0.82-0.97)$ & 110 & 157 & 5 & 60 \\
\hline & & $\geqslant 763.5 \mathrm{kU} \cdot \mathrm{L}^{-1}$ & $0.08(0.04-0.14)$ & $0.95(0.92-0.98)$ & $0.47(0.25-0.71)$ & $0.66(0.61-0.71)$ & 9 & 10 & 106 & 207 \\
\hline \multirow[t]{2}{*}{ FeNO + blood eosinophils } & $0.87(0.83-0.91)$ & $\geqslant 0.095^{\#}$ & $0.95(0.90-0.99)$ & $0.39(0.32-0.46)$ & $0.45(0.39-0.52)$ & $0.94(0.86-0.98)$ & 106 & 129 & 5 & 82 \\
\hline & & $\geqslant 0.70^{\#}$ & $0.46(0.36-0.56)$ & $0.95(0.91-0.98)$ & $0.84(0.71-0.91)$ & $0.77(0.71-0.82)$ & 51 & 10 & 60 & 201 \\
\hline
\end{tabular}

Data are presented as $n$, unless otherwise stated. $n=336$. AUC: area under the curve; PPV: positive predictive value; NPV: negative predictive value; Feno: fraction of exhaled nitric oxide; Ig: immunoglobulin. \#: All test combinations were log transformed; these values correspond to an individual's probability of sputum eosinophilia, as determined by the formula provided in online supplementary figure E3.

TABLE 3 Diagnostic accuracy in in patients with different asthma phenotypes

\begin{tabular}{|c|c|c|c|c|c|c|c|c|c|c|c|c|}
\hline & \multicolumn{3}{|c|}{ Obesity } & \multicolumn{3}{|c|}{ Atopy } & \multicolumn{3}{|c|}{ Asthma severity } & \multicolumn{3}{|c|}{ Smoking status } \\
\hline & Nonobese & Obese & p-value & Nonatopic & Atopic & $\mathrm{p}$-value & Mild-moderate & Severe & p-value & Never-smoker & $\begin{array}{l}\text { Ex- or current } \\
\text { smoker }\end{array}$ & p-value \\
\hline $\begin{array}{l}\text { Eosinophilia } \\
|<3 \% / \geqslant 3 \%|\end{array}$ & $154 / 82$ & $66 / 34$ & 0.90 & $153 / 74$ & $67 / 42$ & 0.28 & $161 / 58$ & $58 / 57$ & $<0.01$ & $103 / 51$ & $117 / 65$ & 0.62 \\
\hline FenO & $0.83(0.77-0.88)$ & $0.78(0.68-0.89)$ & 0.46 & $0.83(0.77-0.89)$ & $0.78(0.69-0.88)$ & 0.40 & $0.81(0.74-0.88)$ & $0.83(0.75-0.91)$ & 0.67 & $0.84(0.77-0.90)$ & $0.81(0.73-0.88)$ & 0.52 \\
\hline $\begin{array}{l}\text { Blood } \\
\text { eosinophils }\end{array}$ & $0.83(0.77-0.89)$ & $0.82(0.73-0.91)$ & 0.82 & $0.83(0.77-0.89)$ & $0.83(0.74-0.91)$ & 0.99 & $0.82(0.76-0.89)$ & $0.80(0.72-0.89)$ & 0.73 & $0.86(0.79-0.93)$ & $0.80(0.73-0.87)$ & 0.23 \\
\hline IgE & $0.73(0.67-0.80)$ & $0.59(0.47-0.70)$ & 0.03 & $0.75(0.68-0.82)$ & $0.57(0.46-0.68)$ & $<0.01$ & $0.68(0.61-0.76)$ & $0.66(0.56-0.76)$ & 0.70 & $0.64(0.55-0.73)$ & $0.74(0.66-0.81)$ & 0.13 \\
\hline $\begin{array}{l}\text { FeNO + blood } \\
\text { eosinophils }\end{array}$ & $0.88(0.83-0.93)$ & $0.85(0.76-0.93)$ & 0.55 & $0.88(0.82-0.92)$ & $0.85(0.77-0.93)$ & 0.63 & $0.86(0.81-0.92)$ & $0.85(0.78-0.92)$ & 0.81 & $0.88(0.82-0.94)$ & $0.86(0.80-0.92)$ & 0.64 \\
\hline
\end{tabular}

Data are presented as $\mathrm{n}$ or area under the curve (AUC) $(95 \% \mathrm{CI})$, unless otherwise stated. AUC $(95 \% \mathrm{CI})$ is given per biomarker in every subgroup. The difference between the AUCs for every biomarker is compared within the separate subgroups and the result depicted as p-value. Bold type represents statistical significance. Feno: exhaled nitric oxide fraction; Ig: immunoglobulin. 
FIGURE 1 Receiver operating characteristic curves for exhaled nitric oxide fraction ( $\mathrm{FeNO})$, blood eosinophils, total immunoglobulin (Ig)E and a combined model. $n=336$.

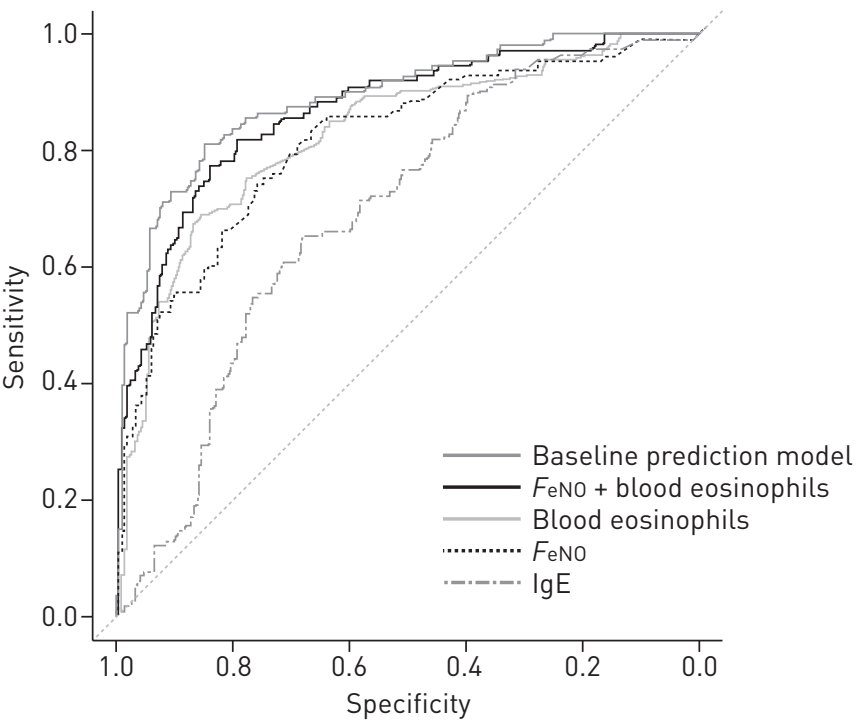

and blood eosinophils into one model improves the overall diagnostic accuracy. The results suggest that FeNO and blood eosinophils (but not total IgE) can be used to confirm or exclude sputum eosinophilia with high certainty in up to half of adult asthma patients, irrespective of asthma phenotype.

The present study is the first to compare the diagnostic accuracy of FeNO, blood eosinophils, total IgE and their combinations between different adult asthma phenotypes. Previous studies have mainly investigated the diagnostic accuracy of these biomarkers in general asthma populations. Our findings in the total study group of asthma patients on FeNO, blood eosinophils and total IgE are in line with the results of these previous studies, which we recently summarised in a systematic review [26], in which we found a pooled AUC of 0.75 for FeNO, 0.78 for blood eosinophils and 0.65 for total IgE. Our findings on FeNO and blood eosinophils are more promising than those of two other recent reports $[10,27]$ in which the authors concluded that $\mathrm{FeNO}$ and blood eosinophils lack sufficient sensitivity or specificity to be useful as markers of sputum eosinophilia. In addition, we developed a combination model of FeNO and blood eosinophils, which increased the diagnostic accuracy significantly compared to the separate markers. Adding four clinical variables to the model further increased the AUC, although only to a very minimal extent. For clinical purposes the use of two variables is obviously more practical.

The diagnostic accuracy of FeNO and blood eosinophils in detecting sputum eosinophilia was similar in the different asthma phenotypes. This may be surprising, since remarkable differences in airway eosinophilia and its associated cytokines and markers have been described in specific asthma subgroups; for example, between obese and nonobese asthma patients [28]. One study showed more eosinophils in the airway submucosa than in the airway lumen of obese patients with asthma, and higher levels of interleukin-5 in bronchoalveolar lavage fluid [13]. Apparently, only a subset of obese asthma patients with eosinophilic airway inflammation shows sputum eosinophilia. In our study, total IgE was relatively more accurate in predicting sputum eosinophilia in nonobese patients compared to obese patients, but had lower diagnostic accuracy than the other two biomarkers. Discordance between different biomarkers for airway eosinophilia has been reported previously $[17,29]$. More interestingly, discordance between various biomarkers of the effects of anti-inflammatory therapy or ability to predict asthma attacks have also been noted [7, 29, 30]. These data suggest that discordance between biomarkers in different asthma phenotypes may point towards different underlying mechanisms.

There was no significant difference in diagnostic accuracy of FeNO and blood eosinophils between atopic and nonatopic patients. One previous study showed lower diagnostic accuracy for FeNO in nonatopic patients than in atopic patients [8]. The discrepancy between these results and ours could be due to differences in patient characteristics or the devices used to measure FeNO. The higher diagnostic accuracy of total IgE in nonatopic patients compared to atopic patients might be related to different underlying mechanisms. While eosinophilia in classical atopic asthma is likely to be T-helper (Th)2-cell driven and includes higher basal IgE production, in nonatopic asthma there is accumulating evidence that activation of eosinophils might be mediated by alternative pathways [14].

Patients with severe asthma often show discrepancies between airway and blood eosinophilia, which is probably explained by their high doses of inhaled or oral corticosteroid treatment. We did not find a 

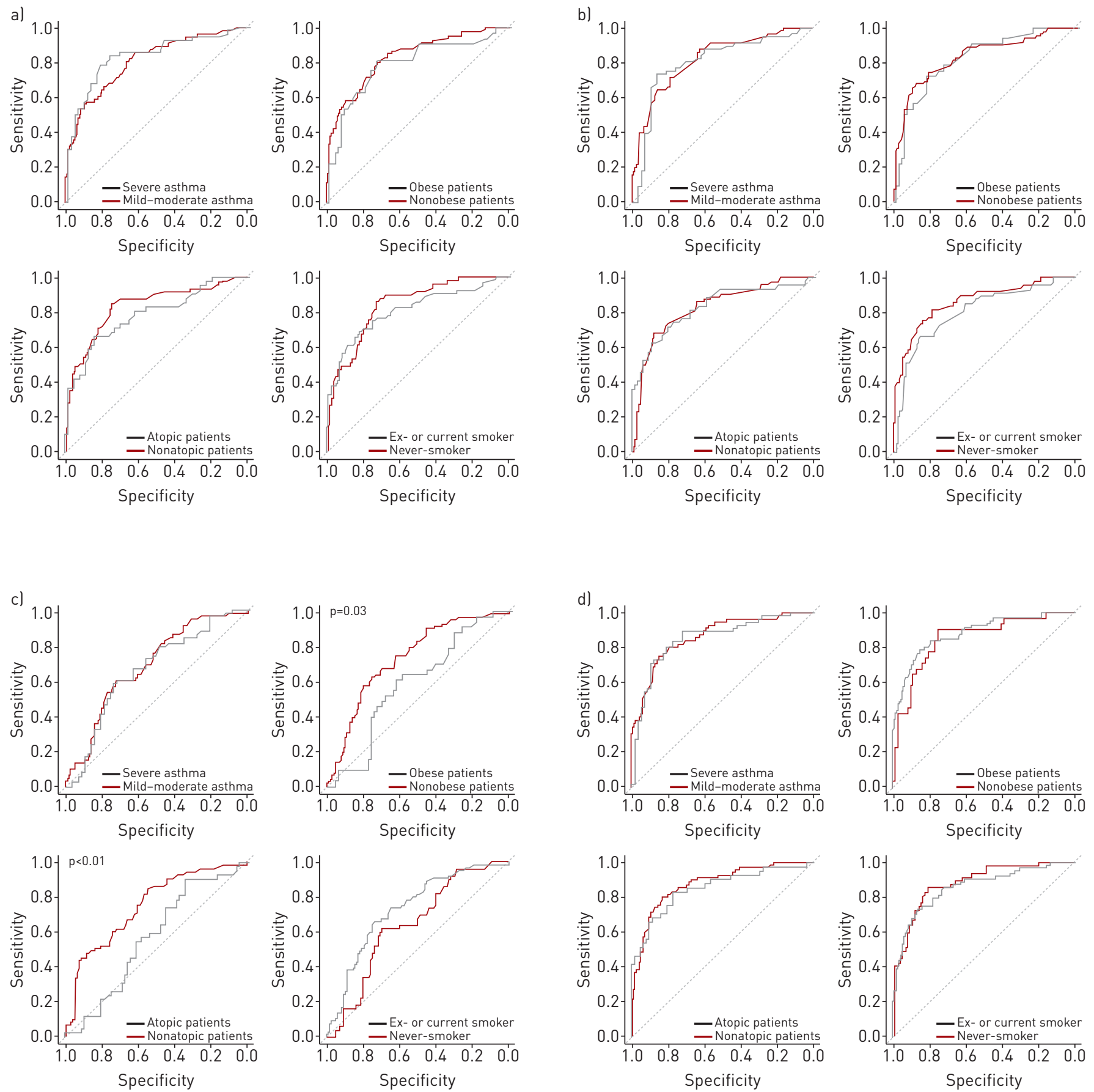

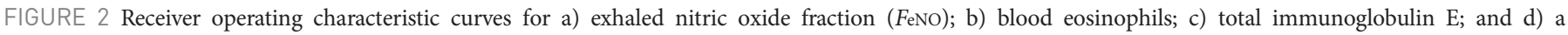
combined model (FeNO and blood eosinophils) in patients with different asthma phenotypes.

difference in the diagnostic accuracy of blood eosinophils or FeNO between mild-to-moderate and severe asthma patients, but previous studies have found conflicting results. One study found an AUC of blood eosinophils of 0.55 in corticosteroid-treated patients and of 0.73 in untreated patients [31], whereas these numbers were 0.75 and 0.62 , respectively, in another study [10]. Three previous studies evaluated the accuracy of FeNO among severe/treated and mild/untreated asthma patients $[8,10,32]$. None of them found considerable differences in the differences in the AUCs. Remarkably, despite comparable AUCs for FeNO and blood eosinophils in our study, the upper threshold range for blood eosinophils was relatively wide due to the higher threshold in patients with severe asthma compared to the other asthma phenotypes (tables 4 and E10). Apparently, a subset of patients with severe asthma shows elevated levels of blood eosinophils without evidence of airway eosinophilia, which confirms previous findings [12]. Circulating 
TABLE 4 Distribution of marker thresholds at $95 \%$ sensitivity and specificity in different asthma phenotypes

Lower threshold sensitivity $\geqslant 95 \%$ Upper threshold specificity $\geqslant 95 \%$

\begin{tabular}{lcc}
\hline FeNO ppb & $8.6-15.1$ & $48.5-69.5$ \\
Blood eosinophils $\times 10^{9}$ cells $\cdot \mathrm{L}^{-1}$ & $0.06-0.095$ & $0.34-0.73$ \\
Total IgE $\mathbf{k U} \cdot \mathrm{L}^{-1}$ & $8.5-25.5$ & $389-2181$ \\
FeNO + blood eosinophils & $0.086-0.138^{\#}$ & $0.656-0.75^{\#}$
\end{tabular}

Data are presented as ranges. FeNO: exhaled nitric oxide fraction; Ig: immunoglobulin. \#: All test combinations were log transformed; these values correspond to an individual's probability of sputum eosinophilia, as determined by the formula provided in online supplementary figure E3.

eosinophils might serve as a reservoir in these patients, thereby maintaining airway inflammation, which cannot be adequately suppressed by inhaled corticosteroids.

Smoking in asthma has often been associated with neutrophilic airway inflammation [15] and enhancement of Th2 mediated inflammation [33], and has also been shown to be associated with reduced FeNO levels [34]. Therefore, (ex-)smoking could have had an effect on the diagnostic accuracy of FeNO to detect sputum eosinophilia [8,9]. A previous study found a lower AUC for FeNO among smokers compared to nonsmokers (0.63 versus 0.77$)$ [8], but this was not the case in our study. This suggests that even in smokers and ex-smokers FeNO can be used as a biomarker for sputum eosinophilia.

The major strength of our study is the large number and the extensive characterisation of the patients, which enabled us to investigate clinical (sub)phenotypes of adult-onset asthma. Another strength is that we reported biomarker thresholds at either high sensitivity or high specificity. These cut-off points are more useful for practising physicians to confirm or exclude airway eosinophilia with high certainty. However, a limitation of this approach is that this method only gives a clear outcome in up to half of the patients; the remainder still need to undergo sputum induction to confirm or exclude sputum eosinophilia. Another possible limitation of our study is the number of missing sputum samples, in particular in patients with mild-to-moderate asthma. This limits the extrapolation of our results to all patients with adult asthma. However, unsuccessful sputum induction in mild-to-moderate asthma might be indicative of a low level of sputum eosinophils, which fits in with the observed lower level of blood eosinophils in this group.

Our study has clinical implications. First, it shows that in a large subset of adult patients airway eosinophilia can be identified with high certainty by using FeNO and blood eosinophils instead of induced sputum. Second, it shows that the accuracy of these biomarkers is similar in various subtypes and severities of asthma. Currently, FeNO and blood eosinophils are mainly used in clinical trials to identify patients with eosinophilic asthma who are eligible for treatment with novel targeted therapies. For example for mepolizumab, a blood eosinophil cut-off of $>0.15 \times 10^{9}$ cells $\cdot \mathrm{L}^{-1}$ was introduced to detect eosinophilic asthma and predict reduction of asthma exacerbations [35]. Our data show that this is an adequate threshold to detect eosinophilia, since an eosinophil count $<0.09 \times 10^{9}$ cells $\cdot \mathrm{L}^{-1}$ is associated with absence of airway eosinophilia in $92 \%$ of patients. Still, consensus about the respective biomarker thresholds is needed, as well as an algorithm and external validation that incorporates a combination of biomarkers.

In conclusion, we showed that FeNO and blood eosinophils have a comparable diagnostic accuracy to identify airway eosinophilia in adult asthma patients irrespective of phenotypic characteristics such as asthma severity, atopy, obesity and smoking status, and, possibly, irrespective of underlying pathways leading to airway eosinophilia. In future clinical trials and day-to-day practice both markers, preferably in combination, may become the preferred method to assess eosinophilic airway inflammation and to guide targeted treatment in adult asthma patients with different phenotypes.

\section{References}

1 Amelink M, De Groot JC, De Nijs SB, et al. Severe adult-onset asthma: a distinct phenotype. J Allergy Clin Immunol 2013; 132: 336-341.

2 Simpson JL, Scott R, Boyle MJ, et al. Inflammatory subtypes in asthma: assessment and identification using induced sputum. Respirology 2006; 11: 54-61.

3 Petsky HL, Kynaston JA, Turner C, et al. Tailored interventions based on sputum eosinophils versus clinical symptoms for asthma in children and adults. Cochrane Database Syst Rev 2007; 2: CD005603.

4 Cowan DC, Cowan JO, Palmay R, et al. Effects of steroid therapy on inflammatory cell subtypes in asthma. Thorax 2010; 65: 384-390.

5 Berry M, Morgan A, Shaw DE, et al. Pathological features and inhaled corticosteroid response of eosinophilic and non-eosinophilic asthma. Thorax 2007; 62: 1043-1049. 
Chung KF, Wenzel SE, Brozek JL, et al. International ERS/ATS guidelines on definition, evaluation and treatment of severe asthma. Eur Respir J 2014; 43: 343-373.

7 Pavord ID, Bafadhel M. Exhaled nitric oxide and blood eosinophilia: independent markers of preventable risk. J Allergy Clin Immunol 2013; 132: 828-829.

8 Berry MA, Shaw DE, Green RH, et al. The use of exhaled nitric oxide concentration to identify eosinophilic airway inflammation: an observational study in adults with asthma. Clin Exp Allergy 2005; 35: 1175-1179.

9 Schleich FN, Seidel L, Sele J, et al. Exhaled nitric oxide thresholds associated with a sputum eosinophil count $\geqslant 3 \%$ in a cohort of unselected patients with asthma. Thorax 2010; 65: 1039-1044.

10 Hastie AT, Moore WC, Li HS, et al. Biomarker surrogates do not accurately predict sputum eosinophil and neutrophil percentages in asthmatic subjects. J Allergy Clin Immunol 2013; 132: 72-80.

11 Schleich FN, Manise M, Sele J, et al. Distribution of sputum cellular phenotype in a large asthma cohort: predicting factors for eosinophilic vs neutrophilic inflammation. BMC Pulm Med 2013; 13: 11.

12 Schleich FN, Chevremont A, Paulus V, et al. Importance of concomitant local and systemic eosinophilia in uncontrolled asthma. Eur Respir J 2014; 44: 97-108.

13 Cohn L, Woodruff PG. Update in asthma 2013. Am J Respir Crit Care Med 2014; 189: 1487-1493.

14 Brusselle GG, Maes T, Bracke KR. Eosinophils in the spotlight: eosinophilic airway inflammation in nonallergic asthma. Nat Med 2013; 19: 977-979.

15 Thomson NC, Chaudhuri R, Heaney LG, et al. Clinical outcomes and inflammatory biomarkers in current smokers and exsmokers with severe asthma. J Allergy Clin Immunol 2013; 131: 1008-1016.

16 Pavord ID, Brightling CE, Woltmann G, et al. Non-eosinophilic corticosteroid unresponsive asthma. Lancet 1999; 353: 2213-2214

17 Lemière C, Ernst P, Olivenstein R, et al. Airway inflammation assessed by invasive and noninvasive means in severe asthma: eosinophilic and noneosinophilic phenotypes. J Allergy Clin Immunol 2006; 118: 1033-1039.

18 Amelink M, de Nijs SB, de Groot JC, et al. Three phenotypes of adult-onset asthma. Allergy 2013; 68: 674-680.

19 Westerhof GA, Vollema EM, Weersink EJ, et al. Predictors for the development of progressive severity in new-onset adult asthma. J Allergy Clin Immunol 2014; 134: 1056-1056.

20 Global Initiative for Asthma. Global Strategy for Asthma Management and Prevention 2014 (update). www. ginasthma.org/local/uploads/files/GINA_Pocket_2014_Jun11.pdf Date last accessed: July 2014. Date last updated: June 2014.

21 Bel EH, Sousa A, Fleming L, et al. Diagnosis and definition of severe refractory asthma: an international consensus statement from the Innovative Medicine Initiative (IMI). Thorax 2011; 66: 910-917.

22 Juniper EF, Bousquet J, Abetz L, et al. Identifying "well-controlled" and "not well-controlled" asthma using the Asthma Control Questionnaire. Respir Med 2006; 100: 616-621.

23 Juniper EF, O’Byrne PM, Guyatt GH, et al. Development and validation of a questionnaire to measure asthma control. Eur Respir J 1999; 14: 902-907.

24 Paggiaro PL, Chanez P, Holz O, et al. Sputum induction. Eur Respir J 2002; 20: Suppl. 37, 3s-8s.

25 Dweik RA, Boggs PB, Erzurum SC, et al. An official ATS clinical practice guideline: interpretation of exhaled nitric oxide levels (FeNO) for clinical applications. Am J Respir Crit Care Med 2011; 184: 602-615.

26 Korevaar DA, Westerhof GA, Wang J, et al. Diagnostic accuracy of minimally invasive markers for detection of airway eosinophilia in asthma: a systematic review and meta-analysis. Lancet Respir Med 2015; 3: 290-300.

27 McGrath KW, Icitovic N, Boushey HA, et al. A large subgroup of mild-to-moderate asthma is persistently noneosinophilic. Am J Respir Crit Care Med 2012; 185: 612-619.

28 Van Veen IH, Ten Brinke A, Sterk PJ, et al. Airway inflammation in obese and nonobese patients with difficult-to-treat asthma. Allergy 2008; 63: 570-574.

29 Cowan DC, Taylor DR, Peterson LE, et al. Biomarker-based asthma phenotypes of corticosteroid response. J Allergy Clin Immunol 2015; 135: 877-883.

30 Haldar P, Brightling CE, Hargadon B, et al. Mepolizumab and exacerbations of refractory eosinophilic asthma. N Engl J Med 2009; 360: 973-984.

31 Liang Z, Zhao H, Lv Y, et al. Moderate accuracy of peripheral eosinophil count for predicting eosinophilic phenotype in steroid-naïe non-atopic adult asthmatics. Intern Med 2012; 51: 717-722.

32 Tseliou E, Bessa V, Hillas G, et al. Exhaled nitric oxide and exhaled breath condensate pH in severe refractory asthma. Chest 2010; 138: 107-113.

33 Polosa R, Thomson NC. Smoking and asthma: dangerous liaisons. Eur Respir J 2013; 41: 716-726.

34 Bjermer L, Alving K, Diamant Z, et al. Current evidence and future research needs for FeNO measurement in respiratory diseases. Respir Med 2014; 108: 830-841.

35 Katz LE, Gleich GJ, Hartley BF, et al. Blood eosinophil count is a useful biomarker to identify patients with severe eosinophilic asthma. Ann Am Thorac Soc 2014; 11: 531-536. 